\title{
An electrode hookup for eyelid conditioning*
}

\author{
BRUCE OSBORNE and TOM ROACH \\ Trent University, Peterborough, Ontario, Canada \\ LORNA GENDREAU \\ Brockville Psychiatric Hospital, Brockville, Ontario, Canada \\ and \\ PAUL GENDREAU \\ St. Patrick's College, Carleton University, Ottawa, Ontario, Canada
}

\begin{abstract}
A method for recording eyelid CRs, using skin electrodes rather than the usual mechanical connection to the S's eyelid, is described. Data are presented to show the comparability of the two recording systems.
\end{abstract}

The study of classical eyelid conditioning with some $\mathrm{S}$ zamples (e.g., senile Ss, 60-90 years old) is complicated by individual reactions to the standard fine-wire hookup. To bypass these reactions, we decided to replace the commonly used mechanical detection system with an electrical one. This methodological change necessitated an estimate of the equivalence of the two recording systems. We assumed that the two techniques would provide similar data.

\section{METHOD}

In order to compare the two methods, 29 first-year introductory psychology students (mean age 21.7 years) underwent classical eyelid discrimination conditioning with movement of the eyelid recorded simultaneously by electrical and mechanical means.

The electrical hookup used Beckman biopotential skin electrodes, $16 \mathrm{~mm}$ in diam. The positive electrode was placed just above the eyebrow; the negative electrode was placed just below the cheekbone, beside the nose. A ground electrode was placed on the fleshy part of the cheek. Attachment of the electrode was made with Beckman electrode paste and collars.

The mechanical hookup (fine wire and potentiometer) was made in the usual manner using a headband. The technique is similar to that first used by Grant, Schipper, and Ross (1952). Figure 1 depicts the mechanical connection and the attachment of the electrodes.

The electrodes were coupled to a Beckman Type 9859 direct nystagmus coupler leading into a Beckman Type 461B preamplifier and 462 amplifier, all mounted in a Beckman RS dynograph recorder. The preamplifier was set to $2 \mathrm{mV} / \mathrm{cm}$, the power amplifier was set at .1, and the filter on the coupler set at a value of 1 . The power amplifier "HI" filter was switched to "out."

The potentiometer of the mechanical hookup was connected to a Beckman Type 9803 strain gauge coupler, a Type 461B preamplifier, and Type 462 power amplifier. The preamplifier was set to $20 \mathrm{mV} / \mathrm{cm}$, and the power amplifier was set at 1.0 ; the "HI" filter was also switched to "out." The above was mounted

*Trent University science grants and APA Grant 0336 to P. Gendreau helped support methodological changes in the laboratory. Reprint requests and a more detailed report of the laboratory setup may be obtained from Bruce Osborne, Psychology Department, Trent University, Peterborough, Ontario, Canada. in the same Beckman Type RS dynograph recorder as the electrode. Thus, the pen output for both detection methods was made simultaneously on the same paper tape. The paper output speed was $125 \mathrm{~mm} / \mathrm{sec}$.

During the conditioning session, Ss were presented with a total of 80 trials ( $40 \mathrm{CS}+$ and $40 \mathrm{CS}_{-}$) in a Gellerman series. Intertiral intervals of 6,9 , or $12 \mathrm{sec}$ were varied randomly.

The CSs were $800-\mathrm{msec}, 65-\mathrm{dB}$ tones of 1,000 and $1,800 \mathrm{~Hz}$, with an interstimulus interval of $800 \mathrm{msec}$ and a UCS duration of $100 \mathrm{msec}$. The UCS was intense enough to support a $100-\mathrm{mm}$ column of mercury.

Ss were given a neutral instruction set before the equipment was attached. The instructions merely involved telling Ss to neither aid nor prevent blinks (e.g., Gendreau \& Suboski, 1971, p. 380 ).

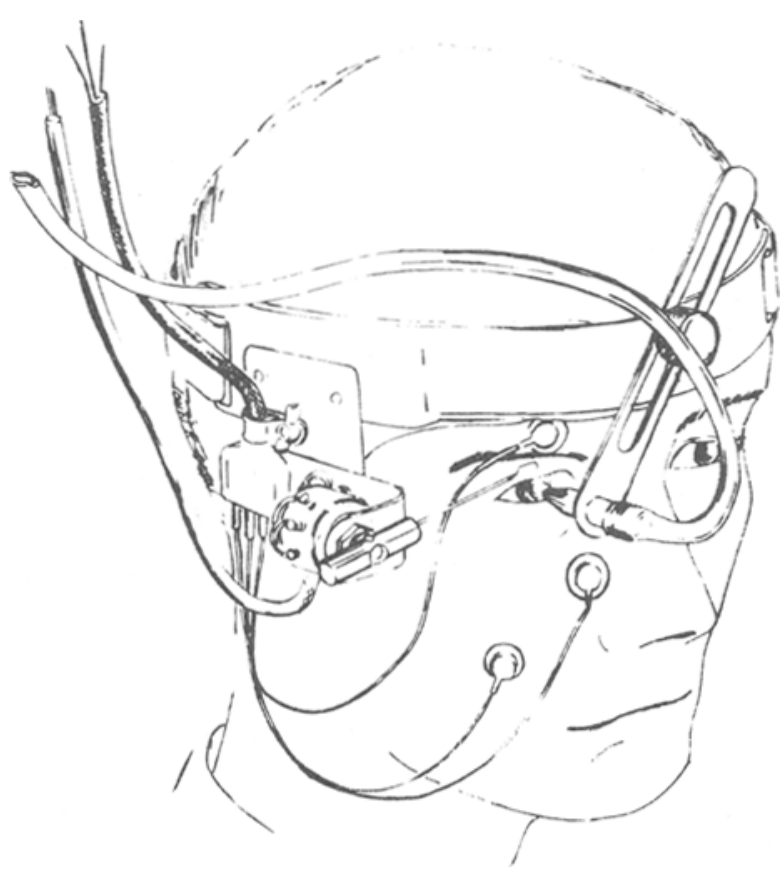

Fig. 1. A drawing of the ey elid mechanical hookup requiring headpiece potentiomter with fine-wire and electrode system. 

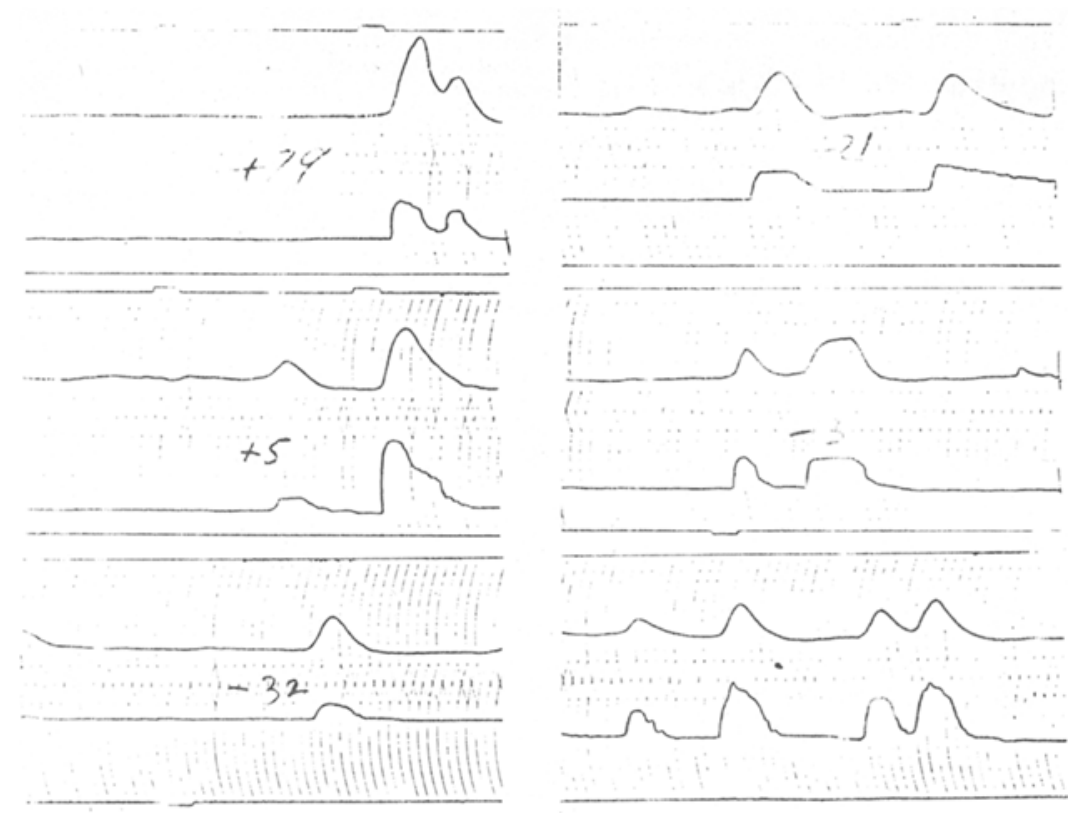

Fig. 2. CRs and UCRs recorded under the electrode (top trace) and mechanical systems (bottom trace).

\section{RESULTS}

$S$ responses were scored for both the mechanical and electrode recording systems. A CR was defined as a 1.0-mm downward movement of the eyelid occurring in the interval between 150 and $800 \mathrm{msec}$ following CS presentation. The mechanical system recorded a $1.0-\mathrm{mm}$ eyelid closure as a $2.0-\mathrm{mm}$ upward pen deflection of the eyelid trace; the corresponding upward pen deflection of the electrode system was $3.5 \mathrm{~mm}$. Slopes and latencies of CRs to CS+ were also measured (see Gendreau \& Suboski, 1971).

Figure 2 shows representative samples of eyelid movements made with both recording systems for CS+ and CS- trials: (a) Trial CS+79 shows UCRs; (b) Trial CS +5 shows CRs followed by UCRs; (c) Trial CS- 32 shows CRs to CS-; (d) Trial CS+ 21 shows sensitization responses followed by UCRs; (e) Trial CS- 3 represents sensitized responses followed by CRs made between 150 and $800 \mathrm{msec}$; (f) free eyelid responding with no CS or UCS presented. The top row of responses in each sample were recorded via the electrode system, those on the bottom by the mechanical. The electrode system produced a trace somewhat smoother than the mechanical hookup, less abrupt in rise time, and generally preceding the mechanical trace by approximately $15 \mathrm{msec}$.

A $1.0-\mathrm{mm}$ eyelid closure or CR scored under the mechanical system was invariably recorded via the electrode system. A small percentage of disagreements (7\%) were due to a legitimate 1-mm upward (opening) eyelid movement. This occurred when an $\mathrm{S}$, after visually fixating before a trial run, opened his eyes wider after CS onset. In this special case, the mechanical system recorded a slight (less than $1 \mathrm{~mm}$ ) pen movement, while the electrode system registered a CR if the upward movement of the eyelid was at least $1 \mathrm{~mm}$. Upward-eyelid-movement CRs were rare and appeared with two Ss whose adaptive reponse to the UCS was to open the eyes wider in a "fixed stare" fashion. The responses of these Ss were within the $150-800-\mathrm{msec}$ interval. The responses were reliable and regular and were scored as CRs under the electrode system.

Latencies for CRs to both CS+ and CS- were compared for trials on which both systems produced CRs. Averaged for all Ss, the mean CR latency for the electrode and mechanical hookups was 518.4 and $533.6 \mathrm{msec}$, respectively, with respective standard deviations of 93.8 and $104.9 \mathrm{msec}$. The mean correlation for latencies scored under both systems was $r=.90$, $\mathrm{p}<.01$.

The two recording methods were also compared for voluntary responding. One definition of a voluntary responder (V) is any $\mathrm{S}$ whose mean CR slope (CRs to CS+ only) is $60 \%$ of his UCR slope (e.g., Gendreau \& Suboski, 1971). In order to obtain reliable determinations of $V$ responders, Ss who produced three CRs or less to CSt and/or three UCRs or less were eliminated from this specific comparison. Twenty-five Ss produced four or more CRs to CSt and four or more UCRs. Their individual CR/UCR slope ratios were computed for each recording system. The ratios yielded a correlation of $r=.90, p<.01$. A CR/UCR slope ratio of .65 on the electrode system was equivalent to the .60 value used as a criterion for $V$ responders with the mechanical system.

Gormezano (1966, pp. 397-398) reported that placing electromyograph electrodes in the orbital region of the eye to detect eyeblinks resulted in a record contaminated by eyeball movements. In our study, 
placement of the electrodes on senile and/or college Ss resulted in no such contamination from eyeball movements, talking, or chewing gum during the conditioning period.

\section{REFERENCES}

Gendreau, P., \& Suboski, M. D. Intelligence and age in discrimination conditioning of the eyelid response. Journal of
Experimental Psychology, 1971, 89, 379-382.

Gormezano, I. Classical conditioning. In J. B. Sidowski (Ed.), Experimental methods and instrumentation. New York: McGraw-Hill, 1966. Pp. 385-420.

Grant, D. A., Schipper, L. M., \& Ross, B. M. Effects of intertrial interval during acquisition on extinction of the conditioned eyelid response following partial reinforcement. Journal of Experimental Psychology, 1952, 44, 203-210.

(Received for publication March 19, 1974; revision received April 20, 1974.) 